\title{
Productivity of Industrial Capital and Labor, Kurdistan Region, Iraq (1995-2008)
}

\author{
Mousa Tawfeeq ${ }^{1,}$,, Gerard D'Souza ${ }^{2}$ \\ ${ }^{1}$ Natural Resource Economics, West Virginia University, West Virginia, USA \\ ${ }^{2}$ Agricultural \& Resource Economics Program, West Virginia University, West Virginia, USA
}

Email address:

mmtawfeeq@mix.wvu.edu (M. Tawfeeq),musatawfeeq@gmail.com (M. Tawfeeq)

\section{To cite this article:}

Mousa Tawfeeq, Gerard D’Souza. Productivity of Industrial Capital and Labor, Kurdistan Region, Iraq (1995-2008). International Journal of Business and Economics Research. Vol. 4, No. 6, 2015, pp. 293-300. doi: 10.11648/j.ijber.20150406.14

\begin{abstract}
Productivity is growing in importance in Kurdistan as it evolves into a more formal, market-based economy. The measurement of productivity and factors of production - labor and capital - are important indicators of industrial firm performance, with an increase in productivity positively affecting economic growth. This research attempts to quantify the impacts of labor \& capital on industrial productivity in the Kurdistan region, Iraq. Moreover, the correspondence between a number of hypotheses and empirical findings are examined. Specifically, this research creates a protocol to enable comparison among productivity indicators in production units in industrial firms. We examine the role of capital and labor forces on productivity in industries of Kurdistan over the 1995-2008 period. The study uses the added values of output, the number of workers, and capital value on productivity. Total Factor Productivity (TFP) is another indicator that is estimated in this research. The results indicate that the growth of industrial firms in Kurdistan is influenced more by labor than by capital productivity. The measurement of these effects is 0.65 and 1.42 for labor and capital, respectively. The production function exhibits increasing returns to scale. It can be concluded that labor is more significant to productivity than capital in this region. It reinforces the low level of technology in firms. Capital per worker $(\mathrm{k}=\mathrm{K} / \mathrm{L})$ has a positive and significant effect on productivity in industrial firms of Kurdistan region.
\end{abstract}

Keywords: Productivity, Labor and Capital Productivity, Total Factor Productivity (TFP), Industrial Firms in Kurdistan

\section{Introduction}

Productivity - and its measurement thereof - is growing in importance in Kurdistan. This is particularly true with respect to labor and capital inputs. Schultz (1961) and Becker (1964) were among the first to measure the relationship between input productivity and economic growth. Since then, there have been both parametric and non-parametric approaches to determine productivity using both static and dynamic methods (Mincer, 1974). The main objective of this analysis is to explain the fluctuations and trend in capital and labor productivity in industrial firms. The study area is the Kurdistan Region in Iraq. The main data source is the census of industrial firms and mines from 1995-2008 from the Industry and Commerce Ministry of Kurdistan Regional Government (KRG).

Industrial firms in Kurdistan Region have many problems, For example some firms exhibit low competitiveness and lower level of technology (Mohammad, 1998). On the other hand, there is no information about productivity in this region. Thus, the main questions are: What effects do inputs (labor and capital) have on output? How much are the elasticity of labor and capital in industrial firms in Kurdistan region? How can the challenges of the industrial sector in Kurdistan Region be solved?

\section{Background}

The word 'productivity' has strong historical origins. François Kenna (1694-1774) stated "land and the agricultural sector are two resources for increasing real wealth and productivity". Adam Smith (1723-1790) stated "productivity is the relationship between labor force and production." Initially research on productivity examined the role of capital and technology in industrial development (Grliches, et al, 1998). Setohuraman (1974) studied productivity in the Indian economy and the results of his research show that the commerce sector has significant productivity. 
Productivity growth was the same in all sectors within the Turkish economy and commercial limitations affected industrial productivity (Crocer and Teneser, 1982). Industrial productivity in Iraq is $74 \%$ lower than South Korea (United Nations Development Program, UNDP, 1998).

Productivity measurement can be difficult to calculate. Empirically, the key issue is that depreciation rates differ widely among assets. For example, depreciation rates for equipment (particularly computers) are relatively fast. Rates for structures are relatively slow and depreciation of land is negligible, at least for tax purposes. Thus, the approach used gives "more weight in the aggregate to a dollar's worth of equipment than to a dollar's worth of structures owing to the equipment's higher rental price" (Azarbaijani, 1999). Previous literature has clearly distinguished between the role of accumulation of resources through investment and that of assimilation which is related to the productive use of such resources, in attaining economic growth (Maddison, 2001). Accumulation and assimilation may be measured as the contributions of capital and multifactor productivity (MFP) to economic growth. In order to accurately measure the relative importance of these factors, it is imperative to have accurate measures of capital input (Heshmati, 2008). Appropriate measures of capital should take account of the differences in the efficiency of various types and vintages of capital assets. However, when quantifying the contribution of capital and MFP, most studies use a crude measure of aggregate capital input which does not take this into account (Karim, 1999). This issue has gained renewed interest because of the increasing heterogeneity of capital assets, as newer forms of capital such as information and communication technology (ICT) equipment have been introduced into the production process (Park et al., 1996).

A sensitivity analysis suggests that the use of standard capital stock measures causes a downward (upward) bias in the contribution of capital (MFPG) when the share of equipment increases in capital stock (Hulten ,1981). The sensitivity analysis also suggests that the way one chooses to aggregate across various asset types in terms of capital composition and the choice of external versus internal rate of return models is of greater empirical importance than the inclusion or exclusion of corporate taxes and capital gain. We also examined the service lifetime of capital equipment which is an essential element in the measurement of capital input (Pilat, et al., 1987).

Aggregation of industry capital inputs, once measured, can be used to construct measures for more aggregate sectors (Landau \& Jorgenson, 1986). In aggregating capital across industries, the weights used are the industry's shares in the aggregate sector's property income. Since property income is a part of each industry's value added, it is additive across industries. Use of property income in aggregating industry capital is consistent with its use as capital's share in industry TFP measurement and with its use as the total rental cost for the various assets deployed by the industry. It is also consistent with Domar's (1961) idea of an aggregate production model which has been developed from outputs and inputs of the industries of the sector. Use of property income to construct weights for aggregation has some empirical significance in cases where some industries are earning higher rates of return than others. Investors in all industries may face similar ex-ante interest rates and so in theory capital would be allocated to industries in such a way that the rental price of a particular type of asset is the same in all industries. But, as existing evidence suggests that frontier technologies are becoming highly capital-intensive, this covariance would also suggest the need for increasing capital accumulation in poor countries, in order to boost productivity and economic growth (Bonelli, et. al, 1992).

Capital productivity is one of the productivity indices. It shows the investment share in an economic unit of production (capital value to increase production). How much of the growth pattern before and after the fall in inflation is due to changes in capital growth, as opposed to capacity utilization or total factor productivity (TFP) growth? To address this question, we use a cross-country dataset of capital stocks, labor force and TFP growth constructed by Nehru and Dhareshwar (1993), which they have recently updated through 1993. These authors constructed capital stocks from investment flows using the perpetual inventory method, with assumptions about initial stocks based on the steady-state capital/output ratios implied by the same investment flows, and assuming a depreciation rate of $7 \%$. Nehru and Dhareshwar did not have data on employment for a large sample of countries (nor does anyone else to our knowledge), so they used the population between the ages of 15 and 64 as a proxy for employment. Data on capacity utilization are also not available. It is clear from the foregoing that 'TFP growth' will include the effect of changes in the utilization of both labor and capital as well as true productivity changes (Addison, 2004).

The recovery of growth is led by TFP growth rather than by capital growth per worker. Capital growth recovers very late in the process of stabilization (again, caution is required in interpreting these numbers because of the changing sample and the small number of observations as the recovery period lengthens - there are only 11 observations in year 6 , and 9 in year 7). These data suggest that a combination of increased capacity utilization and productivity improvements explains the early years of growth recovery after stabilization; only later does capital growth come in. This result is consistent with what Bruno and Easterly (1995) found over the medium run. There has been other research about the slow response of investment to policy adjustments or, more generally, the slow recovery of investment after a recession (Pindyck, et all, 1993). Serven and Solimano, (1993); Caballero et al., (1995); Blomstrom et al. (1993) have a related finding that investment lags but does not lead growth. In fact, the slow response of investment likely reflects the value of waiting when the permanence of the policy change is uncertainty output ( Dixit, et al., 1994), or as reflecting non-linearities in the minimum scale of investments needed to make any adjustment to capital stocks (Caballero, 1995).

\subsection{The Study Area}

The Kurdistan Region (KR) is an autonomous region of 
Iraq. The regional capital is Erbil, also known as Hawler. The region has been officially governed by the Kurdistan Regional Government since 1991.The Kurdistan Region comprises parts of the four governorates of Erbil, Slemani ,kirkuk ,and Duhok (Figure 1). KR is an emerging market. With a young and increasingly prosperous population of 7.2 million, the region covers about 84,000 square kilometers (around the same size as the Netherlands or Switzerland). There is an abundance of oil and gas resources in the region. The region has more than 50 billion barrels of petroleum reserve. KR is a geostrategic area since it is located among Turkey, Syria, Iraq, and Iran which serves as a bridge for those countries. Moreover, the KR is rich in natural resources and fresh water since it is traversed by the Sirwan river, the Tigris and its tributaries, and the Great Zab and Little Zab. The area is composed primarily of the central and northern Zagros, the eastern two-thirds of the Taurus and Pontus, and the northern half of the Amanus Mountains. Kurdistan rgion is located in North of the Iraq and south of Kurdistan. The population of Kurdistan Region is more than 5,000,000 in 2014. Additionally, more than 30 percent of the industrial firms of Iraq are in Kurdistan Region (Ministry of Industry, MI, 2009).

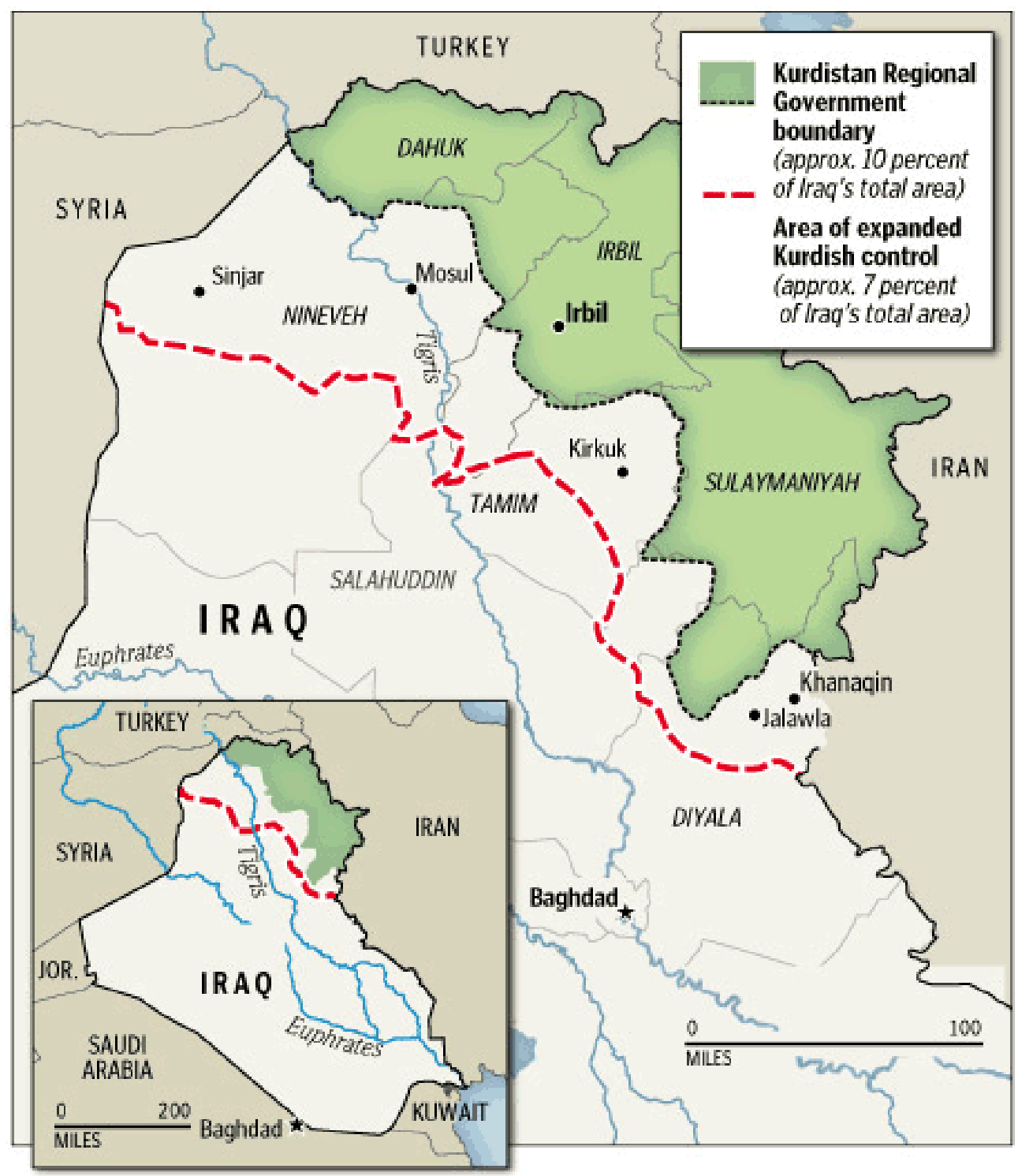

Figure 1. Map of Kurdistan Region (KR).

\section{Methodology and Model}

The objective of this research is the measurement of productivity (labor and capital) and analysis of their changes. Thus, we need to specify a model of the production process which enables both the measurement of productivity and ways to enhance productivity growth as reflected in industrial indices and exports sectors. This research tries to create a comparison between the productivity indices of production factors and production units in the industry sectors. As mentioned before, there are several factors that affect productivity such as Capital labor force productivity directly (Mahadevan, 2002). On the other hand, factors such as innovation, investment, $\mathrm{R} \& \mathrm{D}$, trade, firm size, government policy and inflation affect total productivity (Khan, 2006). Due to the importance of capital and labor in industrial firms, this paper examines the effects of capital and labor on 
industrial productivity in Kurdistan Region. In order to measure the role of capital and labor in industrial firms, this study utilizes the Cobb-Douglas production function. The CD function has elasticity of substitution equals to one and is convex. Thus, we can analyze return to scale and elasticity of substitution. Therefore, we have specified function below:

$$
Y=A K^{\alpha} L^{\beta} e^{t}
$$

Where:

$\mathrm{Y}=$ output (value added), $\mathrm{L}=$ number of workers, $\mathrm{K}=$ capital stock, $\mathrm{A}=$ total factor productivity (TFP) and $\mathrm{e}=$ random disturbance term.

The reason why Cobb-Douglas equation is used in this function is because it exhibits constant return to scale.

Expressed in per capita terms, Equation (1) becomes:

$$
y=A k^{\alpha} L^{\alpha+\beta-1} e^{t}
$$

Where $\mathrm{y}=\mathrm{Y} / \mathrm{L}$ labor productivity, $\mathrm{k}=\mathrm{K} / \mathrm{L}$ capital per worker, $\alpha+\beta-1$ return-to-scale assumption. If $\alpha+\beta=1$ then return to scale is constant.

If we assume that $\alpha+\beta=1$ then we have:

A represents total factor productivity (TFP) thus we have:

$$
y=A k^{\alpha} e^{t}
$$

Also, time is another variable in the technology coefficient:

$$
A=A_{0} e^{\theta+\lambda i(x i)}
$$

Where: $\theta$ is the time effects including the changes in technology (Ballot et. al., 2001), $x i=$ factors that affect productivity. By replacing Equation (4) in (3) we have:

$$
\begin{gathered}
y=A k^{\alpha} L^{\alpha+\beta-1} e^{t} \\
y=A_{0} e^{\theta+\lambda i(x i)} k^{\alpha} l^{\beta} e^{\varepsilon}
\end{gathered}
$$

After taking natural logarithm from (5) we have:

$$
L n y=L n A_{0}+(\theta+\lambda i(x i)) L n e+\alpha L n k+\beta L n l+\varepsilon L n e
$$

The true parameters and true error are never known. Instead we estimate them using a statistical method. On the other hand, some explanatory variables may affect each other, something which negatively influences the fit of our model. In this study, the empirical approach used by Ballot et. al. (2001) and Teal (2004) was employed.

\subsection{Data and Statistics}

The data used in this study come from the survey of industrial firms in the Kurdistan region (ministry of Industry or MOF, 2008). The data which is given to us alongside the research consists of two variables collected from industrial firms in the form of combination cross sectional and time series from 1995 to 2008. The time series data has been used for labor, capital and productivity in the industrial firms in Kurdistan region.

In order to organize the data, we have used International System for Industrial Code (ISIC) classification (UINDO, 2008).

Table 1. Classification on based ISIC.

\begin{tabular}{llll}
\hline ISIC code & ISIC Industrial groups & CHNERY AND SIRKIN & PRODUCTION CLASSIFICATION \\
\hline 31 & Food, beverages, and tobacco & First industries & Consumption industries \\
32 & Textile, wearing garments, and leather products & First industries & Consumption industries \\
33 & Wood and wood products, including furniture & Middle industries & Consumption industries \\
34 & Paper and paper products. & Final industries & Middle industries \\
35 & Chemicals, rubber, and plastic products & Middle industries & Middle industries \\
36 & Nonmetallic mineral products excluding petroleum and coal & Middle industries & Middle industries \\
37 & Basic metal industries & Final industries & industries \\
38 & Fabricated metal products, machinery, and equipment & First industries & \\
39 & Other products & & \\
\hline
\end{tabular}

Source: United Nations industrial development organization (UNIDO)

\section{Other Indicators}

As mentioned formerly, the empirical model used for the study is:

$$
y_{i t}=\beta_{0}+\beta_{1} k_{i t}+\beta_{2} l_{i t}+\theta_{t}+\varepsilon_{i t}
$$

Where,

$\mathrm{i}=(1,2 \ldots \mathrm{n})$ index of firms, and $\mathrm{t}=1995$ till 2008

$\mathrm{yi}=(\mathrm{Yi} / \mathrm{Li})$ value - added per labor in ith firm.

$\mathrm{k}=(\mathrm{K} / \mathrm{L})$ ratio of capital to worker in ith sub-sector.

$\varepsilon=$ error term in ith . $\theta=$ the time effect (Maury,S, et al, 2006).

\subsection{Total-Factor Productivity}

Total-factor productivity (TFP) is a variable which accounts for effects in total output caused by all inputs. For example, a year with unusually good weather will tend to have higher output, because bad weather hinders agricultural output. A variable like weather does not directly relate to unit inputs, so weather is considered a total-factor productivity variable.

The equation below (in Cobb-Douglas form) represents total output (Y) as a function of total-factor productivity (A), capital input $(\mathrm{K})$, labor input $(\mathrm{L})$, and the two inputs' 
respective shares of output ( $\alpha$ is the capital input share of contribution). An increase in either $\mathrm{A}, \mathrm{K}$ and $\mathrm{L}$ will lead to an increase in output. While capital and labor inputs are tangible, total-factor productivity appears to be more intangible as it can reach from technology to knowledge of worker (human capital). The levels of productivity between food industries and total industries are obtained by using Kendrick Index as:

$$
\operatorname{TFP}_{i}=\frac{Y_{i}}{K_{i}^{\alpha} L_{i}^{\beta}}
$$

\subsection{Kendrick Index}

Kendrick uses this way for estimating general productivity changes in the US. General production index is counted according to actual production with production causes (labor and capital):

$$
T F P_{i}=\frac{V_{i}}{\alpha K_{i}+\beta L_{i}}
$$

Divisia index

General productivity index is accounted according to production index in Divisia index.

$$
\mathrm{D}=\mathrm{K}^{\wedge} \alpha \mathrm{L}^{\wedge} \beta
$$

$\alpha$ : share of capital

$\beta$ : share of labor force

$\mathrm{Lt}$ : labor force $\mathrm{Kt}$ : capital

$$
T F P=\frac{V_{i}}{D_{i}}
$$

V: added value

\subsection{Labor Productivity}

The labor force is the main input of production in an industrial unit and it has a significant role in increasing productivity in a firm. This indicator shows the ability and efficiency of each employee in the production process of a specific output.

$$
\frac{Y_{i}}{L_{i}}=l
$$

\subsection{Capital Stock Measurement}

Capital is another important input in the production function. The term capital has a different connotation from the term investment because investment is a way to increase capital. Thus, we can say the capital measurement is a result of investment at a specific time and has a direct relationship with other inputs. Intuitively, capital is an outcome of investment minus accumulated depreciation. Therefore, counting the depreciation value is a way to determine net capital stock for an industrial firm. As mentioned previously, this research refers to making investment in nine industrial groups. (Table

\begin{tabular}{|c|c|c|c|c|c|c|c|c|c|c|}
\hline Year & ISIC 31 & ISIC32 & ISIC33 & ISIC34 & ISIC35 & ISIC36 & ISIC37 & ISIC38 & ISIC39 & TOTAL \\
\hline 1995 & 12 & 2 & 0 & 0 & 52 & 100 & 0 & 12 & 30 & 218 \\
\hline 1996 & 14 & 8 & 0 & 18 & 68 & 141 & 0 & 17 & 41 & 307 \\
\hline 1997 & 18 & 20 & 0 & 45 & 72 & 173 & 0 & 89 & 45 & 462 \\
\hline 1998 & 28 & 59 & 0 & 100 & 76 & 195 & 0 & 100 & 200 & 758 \\
\hline 1999 & 46 & 94 & 0 & 43 & 96 & 219 & 0 & 256 & 320 & 1074 \\
\hline 2001 & 1013 & 2104 & 0 & 69 & 828 & 392 & 0 & 144 & 288 & 3926 \\
\hline 2002 & 1202 & 1405 & 0 & 185 & 2 & 1020 & 79 & 1968 & 393 & 5172 \\
\hline 2003 & 498 & 9767 & 37 & 400 & 54 & 2910 & 72 & 1371 & 860 & 15969 \\
\hline 2004 & 520 & 5910 & 430 & 514 & 68 & 3012 & 168 & 2002 & 950 & 13574 \\
\hline 2005 & 1806 & 9413 & $26-$ & 863 & 972 & 167719 & 59 & 1182 & 138 & 183501 \\
\hline 2006 & 1405 & 23778 & 48 & 5060 & 2150 & 11927 & 336 & 477 & 438 & 45619 \\
\hline 2008 & 10011 & 3666 & 9 & 6895 & 1904 & 7043 & 176 & 10799 & 1148 & 41651 \\
\hline TOTAL & 35366 & 66491 & 546 & 6257 & 6983 & 394807 & 1466 & 16658 & 8906 & 538368 \\
\hline
\end{tabular}
below: Capital stock):

$$
\mathrm{K}_{\mathrm{t}}=\mathrm{K}_{0}+\sum\left(\mathrm{It}-\mathrm{D}_{\mathrm{t}}\right)
$$

Table 2. Capital stock (Million Dinars; 1 Iraqi Dinar $=0.0009$ USD) 1999-2008.

Source: Ministry of Industry, the KRG

\section{Results and Discussion}

Kurdistan is a historical area in handmade industries and art. Kurds were known as skillful in industry and art in the Middle East over 5,000 years ago. Kurdistan is suitable for industrial activities, because there is a strong base of natural resources. From 1995 to 2008, the infrastructure underlying Kurdistan industry has been steadily improving. While Kurdistan has a historical background in industrial products, there has not been proper development in associated technology.

In 1974 , data show that there were 4,125 big industrial firms 
in different fields in Iraq, but only 6 big firms were in the Kurdistan region (Industry ministry, 2008). In addition, in 2004, although there were 322 general big industrial firms in Iraq, only 14 units were in the Kurdistan Region. This industrial workplace had 1,827 personnel which, compared to others, was a low number. In 2008, 20 new general industries have been established in the Kurdistan region.

From 1995 to 2008, the food product industries grew rapidly. There were 25 units in 1986, but they rose to 555 units in 2005. Wood industries grew from 0 units in 1986 and to 13 units in 2005. The statistics of wood industries and wood products were not clear in 2002. The number of chemical industry workplaces from 2002 to 1989 and metal industries from 2003 to 2005 is not clear.

\subsection{Number of Employees}

The study of employment in great industrial working-places shows that each workplace had an average of 12 employees in 2003 and grew to an average of 30 employees in 2008.

\subsection{Added Value}

Added value is one of the industrial indicators. It shows the value of different industrial activities. The added value of a working-place was 810 million Dinars in 2003, but it became 13,709 million Dinars in 2008. In 2002, the high and low added value was in industrial groups. Growth of investment made changes in the added value index from 1995 to 2008.

\subsection{Final Product Value}

Final product has an important role in industry analysis. The products value shows the measure of output in industry. It was 1,206 million Dinars $(\mathrm{d} 5=\$ 1)$ in 1995 and became 25,179 million Dinars in 2005. From 1995 to 2008 food and chemical industries had a good profit and most of the investment was in food industries.

\subsection{Investment Value}

Investment is the base of industrial development and so it has an important role in such development. The growth of investment value was 10.12 in Kurdistan region from 1995 to 2008. The investment value in industrial units was 12 million Dinars in 2002, and grew to 32,341 million Dinars in 2005, with good growth in Kurdistan Region.

In this period metal and food industries had growth rates of about $22 \%$. Also, mineral and weaving industries had a low growth rate, about 5 percent, and other industries growth was about 25 percent from 1995 to 2008 . The highest investment was in mineral industries and it was low in weaving and clothing industries in 2002. The investment in factories of 9.2 million Dinars in 2002 became 26.2 million Dinars in 2005.

\subsection{Model Estimation}

We estimated ten models with ordinary least square (OLS). According to the results in the table above, for food firms, we have increasing returns to scale $(\alpha+\beta>1)$. In addition, the function is homogenous of degree of 1.5. All other industrials firms have increasing returns to scale except group 33 which is wood industrials firms. This group has decreasing returns to scale $(\alpha+\beta<1)$.

Labor productivity

The labor productivity was low and reduced in Sulaimaina industrial units from 1995 to 2008. War in the region and unskilled and lower educated labor forces were the basic reasons that government and people did not invest in the industrial sector, so labor productivity was low. After the war, the Kurdistan region grew, similar to post-world war II US and Europe. In general, labor productivity growth was most impressive at 38 percent in the general industries groups.

Table 3. Econometric models for KR firms.

\begin{tabular}{llllll}
\hline ISIC & Function estimated & DW & $R^{2}$ & F & N \\
\hline 31 & LQ=1.6+0.6LK+0.9LL & 2.55 & 0.95 & 40.4 & 12 \\
32 & LQ=-7.6+0.2lk+2.3LL & 2 & 0.97 & 190.2 & 12 \\
34 & LQ=9/3+0.6LK+0.8LL & & 0.91 & 19.8 & 12 \\
35 & LQ=2.34+0.4lk+0.7LL & 1.85 & 0.82 & 23.4 & 12 \\
36 & LQ=3.03+0.4LK+0.6LL & 1.8 & 0.93 & 68.45 & 12 \\
38 & LQ=5.95+0.03LK+1.35LL & 2.05 & 0.99 & 319.5 & 11 \\
39 & LQ=-3.22+0.6LK+1.3LL & 1.91 & 0.85 & 17.9 & 12 \\
TOTAL & LQ=-5.06+0.23LK+1.8LL & 1.9 & 0.99 & 509.2 & 12 \\
\hline
\end{tabular}

Capital productivity

Capital productivity shows the level of investment in industrial firms. It had negative growth, (about $-6 \%$ ), in industrial groups in Kurdistan region. This negative growth shows the low level of knowledge and industrial development in Kurdistan industries. The total productivity had no growth in the Divisia index, but had a high growth in the Kendrick index from 1995 to 2008 . Wood industries had a successful outcome. The formula of wood production result was: $Y=0.68 K^{0.23} L^{1.8}$. This equation reveals that wood firms are labor intensive and exhibit increasing returns to scale (IRS) in this type of industrial firms.

\subsection{Test of Stationary Error}

The stationary test is one of the most important indicators to analyze the estimation of an econometric model. According to the results achieved in the stationary test, the wood and metal firms were accepted and the others were rejected, i.e., the Ho could not be rejected, which was a surprising result.

H0: Non stationary error term H1: Stationary term (residual)

Table 4. Hypothesis testing.

\begin{tabular}{lllllll}
\hline ISIC & CV & CV & CV & ADF & \multicolumn{2}{l}{ Coefficient } \\
\hline 31 & 0.01 & 0.05 & 0.10 & & D.W & $\mathrm{R}^{\wedge} 2$ \\
32 & -1.63 & -1.9 & -2.79 & -2.5 & 2.32 & 0.84 \\
33 & -1.63 & -1.97 & -2.79 & -3.39 & 1.9 & 0.52 \\
35 & -1.63 & -1.98 & -2.96 & -2.27 & 2.3 & 0.53 \\
36 & -1.6 & -1.9 & -2.7 & -1.78 & 1.78 & 0.62 \\
37 & -1.6 & -1.9 & -2.8 & -3.13 & 1.93 & 0.56 \\
39 & -2.8 & -3.3 & -4.6 & -2.34 & 1.07 & 0.36 \\
TOTAL & -1.6 & -1.9 & -2.8 & -3.16 & 1.92 & 0.84 \\
\hline
\end{tabular}




\subsection{Testing Research Hypotheses}

Productivity measures of products in the industrial firms in Kurdistan region during the years 1995-2008 was equal in such sectors as food, chemical and other common industries. The research leads us to a high level of productivity in KR. The capital productivity shows that most of the economic processes led to a condition of stability. Therefore, there is a fluctuation during the period of study. As previously noted, all of the industries except wood and metal were not very strong historically. The other industries were low early in the years 1995-2008 and high at the end. According to these results, the products of food, paper, minerals, non -metal and machine tools were mostly the same. There are some contrasting aspects in the other industries in Kurdistan which negate the theories. It makes for a better growth condition for other industries like weaving, chemicals and clothes. In other words, there is not a significant relationship between the products and investment field in Kurdistan. The results show that all of the products have a logical output except the mineral (non -metal) industries which had little input. It caused and affected the other economic elements.
Table 5. Estimation of parameters.

\begin{tabular}{lll}
\hline \multirow{2}{*}{ ISIC Industrial groups } & \multicolumn{2}{c}{ Elasticity of L \& K } \\
\cline { 2 - 3 } & B2(LK) & B1(LL) \\
\hline Food, beverages, and tobacco & 0.5 & 0.8 \\
Textile, wearing garments, and leather products & 0.2 & 2.3 \\
Wood and wood products, including furniture & - & - \\
Paper and paper products. & 0.4 & 0.7 \\
Chemicals, rubber, and plastic products & 0.4 & 1.3 \\
Nonmetallic mineral products excluding petroleum & 0.4 & 0.6 \\
and coal & - & - \\
Basic metal industries & & \\
Fabricated metal products, machinery, and & 0.2 & $0 / 9$ \\
equipment & 0.6 & 1.35 \\
Other products & 0.23 & 1.8 \\
TOTAL & \multicolumn{2}{c}{} \\
\hline
\end{tabular}

\subsection{Returns to Scale}

The calculation indicates that except in non-metallic industries the RTS decreased and in food industries the RTS increased. In all other industries, RTS does not change.

The RTS Calculation of Kurdistan industries:

Table 6. Returns to scale.

\begin{tabular}{|c|c|c|c|c|c|}
\hline \multirow{2}{*}{$\begin{array}{l}\text { ISIC } \\
\text { Food, beverages, and tobacco }\end{array}$} & \multicolumn{3}{|c|}{$\mathrm{F}(\alpha, \mathrm{N} 1, \mathrm{~N} 2)$} & \multicolumn{2}{|c|}{ F computed } \\
\hline & 0.01 & 0.05 & 0.10 & $\mathrm{~B} 1+\mathrm{B} 2=1$ & $\mathrm{~B} 1=\mathrm{B} 2$ \\
\hline Textile, wearing garments, and leather products & 8.185 & 4.38 & 2.98 & 14.1 & 0.22 \\
\hline Wood and wood products, including furniture & 8.185 & 4.38 & 2.98 & 0.02 & 0.015 \\
\hline \multicolumn{6}{|l|}{ Paper and paper products. } \\
\hline Chemicals, rubber, and plastic products & 8.185 & 4.38 & 2.98 & 0.86 & 0.05 \\
\hline Nonmetallic mineral products excluding petroleum and coal & 8.185 & 4.38 & 2.98 & 0.896 & 0.09 \\
\hline Basic metal industries & 8.185 & 4.45 & 3.03 & 0.24 & 0.12 \\
\hline \multicolumn{6}{|l|}{ Fabricated metal products, machinery, and equipment } \\
\hline Other products & 8.185 & 4.38 & 2.98 & 0.0014 & 5.5 \\
\hline TOTAL & 8.185 & 4.38 & 2.98 & 1.94 & 4.8 \\
\hline
\end{tabular}

\section{Conclusions}

From 1995 to 2008 food and chemical industries were quite profitable, and more investment was in food industries. There was investment in mineral industries more so than the other industrial firms. The investment in the mineral firms was from 9.2 million Dinars in 2002, which became 26.2 million Dinars in 2005. The labor productivity was low and reduced in Kurdistan region industrial units from 1995 to 2008. War in the region and lack of skilled workers were the basic reasons that the labor productivity were low (38\%). All industrial firms have increasing returns to scale except group 33 which is the wood industry. Before 1995, the growth rate in capital and labor productivity was negative. This negative growth shows the low level of knowledge and industrial development in Kurdistan region's industries. Thus, it is the main reason for non-industrial development in Kurdistan region. Total factor productivity in Kurdistan general industries had a low growth rate with no growth in the Divisia index, but had a high growth rate in the Kendrick index from 1995 to 2008.

\section{References}

[1] Addison T. and A. Heshmati (2004), The New Global Determinants of FDI Flows to Developing Countries: The Impacts of ICT and Democratization, Research in Banking and Finance 4, 151-186.

[2] Azarbaijani,K (1999), Total productivity in farming sector, Gilan, Agriculture development, vol137.

[3] Bitzer, J. and Stephan, A. (2002)" A Schumpeter -inspire Approach to construction of $\mathrm{R} \& \mathrm{D}$ Capital stock and Productivity" journal of econometrics, 46, 213-227.

[4] Baroo J, (2002) "economic growth in a cross section of countries", the quaterly journal of economics, may, p.p103-120.

[5] Branscomb L.M. (2001a), Japan: Model, Mentor, and Competitor, Chapter 9 in: L-M. Branscomb and Y-H. Kim, Eds. Korea at the Turning Point: Innovation-Based Strategies for Development, London: Praeger. 
[6] Branscomb L.M. (2001b), Taiwan: Innovation in SMEs, Chapter 10 in: L-M. Branscomb and Y-H. Kim, Eds. Korea at the Turning Point: Innovation-Based Strategies for Development, London: Praeger. Bonelli, Regis (2002), "Growth of Productivity in Brazilian Industries", j. Devel Econ. 39. PP $85-109$.

[7] Caballero markov (2002), "Productivity Growth in Polish Industry" j. Comparative . Econ. 11, PP. 1-20.

[8] Chung S-C. and L.M. Branscomb (2001), Technological Transfer and International Cooperation, Chapter 13 in: L-M. Branscomb and Y-H. Kim, Eds. Korea at the Turning Point: Innovation-Based Strategies for Development, London: Praeger.

[9] Diwert, W.E. (2003) on productivity measurement in the research paper "The theory of total factor productivity measurement in regulated industries" Academic press, new York.

[10] Hulten (1981), Landau \& Jorgenson (1986) and Jorgenson (2001)., "Productivity and technical change: The case of Tiwan,Applied Economics", vol, 33 No 15, pp 1911-25.

[11] Kim K-D. (2001), Shifting strategies: From cost advantage to superior value, Chapter 5 in: L-M. Branscomb and Y-H. Kim, Eds. Korea at the Turning Point: Innovation.

[12] Lee Y-T. and L.M. Branscomb (2001), Korean Information Technology: Status and Policy Implications, Chapter 14 in: L-M. Branscomb and Y-H. Kim, Eds. Korea at the Turning Point: Innovation-Based Strategies for Development, London: Praeger.

[13] Maddison, A. 2001. The World Economy: A millennial perspective, Development Centre Studies. Paris: OECD.
[14] Mohammad M. (2003), industrial development in Kurdistan, Sulaimania university.

[15] O'Rourke, K.H. 2001. Globalization and Inequality: Historical Trends, NBER 8339, Cambridge MA: NBER.

[16] Park S-R. and H-S. Kim (2001), Promoting the culture of science and innovation, Chapter 6 in: L-M. Branscomb and Y-H. Kim, Eds. Korea at the Turning Point: Innovation-Based Strategies for Development, London: Praeger.

[17] Pindyck and Solimano, 2003 "Productivity measures", http://solstice.Crest.Org/Common/Comment-form.shtml.

[18] Salahadin Hafid (2004), Kurdistan economy, Sulaimania university. vol.1.

[19] Serven and Solimano, (2003), "Growth without productivity" j. Devel. econ, 19 (1/2), pp.25-38.

[20] Pilat, Dirk, shiho M. (2002)" Productivity Growth in Polish Industry. J. Comparative.Econ., 11, PP.1-20.

[21] Pindyck and Solimano, (2003), "trinity Primer.Ntional Productivity Coroporation-Malasia"

[22] Sethuraman, S.V, (2004), Employment And Labor Productivity In Indian Since 1950, Vol, 22(4).

[23] Schultz, T. W. (1961). Investment in human capital. The American economic review, 1-17.

[24] United Nations, Industrial Development Organization, www.UN.ORG/UNIDO. 